\title{
SYNTHESIS AND CHARACTERIZATION OF BIOSURFACTANT USING WASTE FROM OIL PROCESSING INDUSTRY AS SUBSTRATE BY Pseudomonas aeruginosa (MTCC 424)
}

\author{
Ashutosh Mishra ${ }^{1}$ and Rakesh Kumar Trivedi ${ }^{2, *}$ \\ ${ }^{1}$ Department of Chemical Engineering, Dr. Ambedkar Institute of Technology for Handicapped, \\ Kanpur-208024, (U.P.) India \\ ${ }^{2}$ Department of Oil Technology, Harcourt Butler Technical University, \\ Kanpur-208002, (U.P.) India \\ *E-mail: rakeshtrivedi@hotmail.com
}

\begin{abstract}
The purpose of this study was to produce biosurfactant by the waste of vegetable oil (soya bean and rice bran) processing industries like spent bleaching earth which contains approximately 14 to $25 \%$ residual oil respectively. More oil \% was found in the spent on rice bran so here the same was used. The spent bleaching earth is a type of waste solid substance which is generated as an ingredient of the cleansing and decolorization process in the edible oil industry. It is usually deposited in the landfills or waste dumps. Pseudomonas was selected for its nutritional and biochemical versatility as well as for the simplicity of the culture conditions. The process opted for the growth of bacteria was steam sterilization and dry heat sterilization followed by microbial culture in basal salt medium with residual oil. Further biosurfactant was screened by various examination methods such as surface tension measurement, emulsification assay E24, CTAB methylene blue assay, oil dislocation (displacement), drop collapse and effect of environmental factors on biosurfactant activity was studied. Rhamnolipid biosurfactant produced by Pseudomonasaeruginosa is determined by the formation of insoluble ion pairs with various cationic substances. Emulsification index (\%) shows the positive result for drop collapse, oil displacement, and CTAB methylene blue assay. The NMR and FTIR analysis show that the concentration and purely screened Rhamnolipid product contained L-rhamnosyl-b-hydroxydecanoyl-b-hydroxydecanoate (RL1) and L-rhamnosyl L-rhamnosyl-bhydroxydecanoyl-bhydroxydecanoate (RL2). Effect of environmental factors like salt, temperature and $\mathrm{pH}$ on surface tension was studied to analyze the solubility of biosurfactant. The optimum $\mathrm{pH}$ was found 6.8 and the optimum concentration of rhamnolipids produced was $8.5 \mathrm{~g} / 1$.
\end{abstract}

Keywords: Biosurfactant, Spent Bleach Earth, Rice Bran, Pseudomonas aeruginosa, CTAB-MB, NMR, FTIR

(c) RASĀYAN. All rights reserved

\section{INTRODUCTION}

Biosurfactant, which is basically surface-active agents, are synthesized by microorganisms. Biosurfactant is to be used than chemical surfactants because of some very valuable characteristics such as lower toxicity, the very low value of critical micelle concentration, better biodegradability, good environmental compatibility, etc. Biosurfactant has major applications to degradation the pollutants. The production which includes isolation, identification and characterization of biosurfactant by an assortment of microorganisms have already been reviewed deeply ${ }^{1}$. Glycolipids and lipopeptides are some commonly isolated biosurfactant which also includes Rhamnolipids, which is produced by Pseudomonasaeruginosa ${ }^{2}$, sophorolipids from Candida sp. ${ }^{3}$, as well as surfactin and iturin produced by Bacillus subtilis strains ${ }^{4}$. Biosurfactants are classified according to their surface activity and molecular weight. Lower molecular weight surface active agents are called Biosurfactant whereas higher molecular weight substances are called Bio-emulsifier. Some common biosurfactant is glycolipids, phospholipids, polymeric

Rasayan J. Chem., 12(2), 1011-1021(2019)

http://dx.doi.org/10.31788/RJC.2019.1225073

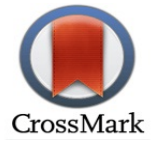


biosurfactants and lipopeptides (surfactin). Among these, rhamnolipids, sophorolipids and trehalolipids are some best popular glycolipids. ${ }^{5}$

To cultivate the bacteria for biosurfactant production, the dairy waste, sugar industry byproducts, fruit and vegetable (edible and no edible oil) processing industries, breweries, distillery, etc. are the major sources. Million ton of hazardous pollutants are treated with biosurfactant to reduce, reuse and recycle the waste. For the laboratory use, some microorganisms and biosurfactants are cultivated from the cheap alternative substrate like waste olive oil crush runoff, dissipate blistering oil, vegetable processing plant squander like spent bleaching earth, soapstock, molasses, whey and distillery waste etc. ${ }^{7-12}$

For increasing the yield of biosurfactant the bacteria cultivation should have the optimal environment and culture conditions to enhance productivity. Some factors affecting biosurfactant production are:
a. C-Source
b. N-Source
c. Salts and minerals
d. Environmental conditions
e. Aeration and Agitation

Biosurfactant has an advantage over chemical surfactant like inferior venomous, superior biodegradability, reduced CMC concentration values, etc. It has an ample variety of relevance in oil, foodstuff and cosmetic industries as well as in therapeutic agent and pollutant removal.

\section{Substrate Used}

\section{EXPERIMENTAL}

RO (Residual Oil) from spent bleaching earth from Kanpur Edible Oil, vegetable oil processing industry situated in Rania, Kanpur.

\section{Microorganisms and Culture Conditions}

Strain Pseudomonas aeruginosa (424) was used which was produced in Microbial Type Culture Collection and Gene Bank (MTCC), Chandigarh.

\section{Apparatus Required}

i. $\quad$ Autoclave: vertical model: PSM-550-B2-11CD was used for steam sterilization of media.

ii. Oven: Make Samsung used for dry heat sterilization.

iii. Laminar air flow: Horizontal make Science Tech Mahindra was used to provide sterilize condition for culture maintenance.

iv. Incubator shaker: Model JEQ-4(0) was used for maintaining growth condition.

v. Separating funnel and water bath are used to separate the phases of different densities and to maintain temperature.

\section{Fermentation Media}

All chemicals of make qualikems $\mathrm{CDH}$ were used. The nutrient issue was cast-off for grounding to inoculums. Main Symphony of the nutrient bisque was warned as beef extort $1.0 \mathrm{~g}$, yeast extorts $2.0 \mathrm{~g}$, peptone $5.0 \mathrm{~g}, \mathrm{NaCl} 5.0 \mathrm{~g}$ in one liter of distilling water. In the nutrient bisque, $15.0 \mathrm{~g}$ of agar is to be added for preparing nutrient agar. The cultures were developed in this bisque for 16-18 $\mathrm{hr}$ at room temperature. The composition is utilized for the synthesis of biosurfactant as per given in Table- 2 and 3 and $4 \%(\mathrm{w} / \mathrm{w})$ residual rice bran oil (RO). The RO in the samples were anticipated by spent through soxlate extraction method using hexane as solvent. The optimum temp was found out at $68^{\circ} \mathrm{C}$ and the optimum time was found 2 hours. It was used as the sole carbon source.

Then microbial culture was incubated for $48 \mathrm{hrs}$ in an incubator shaker at $100 \mathrm{rpm}, 25^{\circ} \mathrm{C}$. The culture was inoculated to basal salt medium (BSM) with each substrate and yeast extract to enhance the growth. They were incubated for $48-72 \mathrm{hrs}$ in an incubator shaker at $100 \mathrm{rpm}, 25^{\circ} \mathrm{C}$. Froth was detected and then centrifuged for $15 \mathrm{~min}$ at $6000 \mathrm{rpm}$ to attain cell gratis supernatant.

\section{Drop Collapse Test}

The method used was developed by Bodour and Maier (1998). ${ }^{14}$ 


\section{Emulsification Test}

The method to determine the EI used was developed by Saravanan, V.et al. 2012. The EI (E 24) is the height $(\mathrm{cm})$ divided by total height $(\mathrm{cm})$, multiplied by $100 .^{15}$

$$
\text { Emulsification Index }(\mathrm{E} 24)=\frac{\text { The height of the emulsion layer achieved }}{\text { total height procured }} \times 100
$$

Table-1: Mineral Salt Medium Compositions

\begin{tabular}{c|c}
\hline Components & Quantity $(\mathrm{g} / \mathrm{l})$ \\
\hline $\mathrm{NaNO}_{3}$ & 1.0 \\
\hline $\mathrm{KH}_{2} \mathrm{PO}_{4}$ & 1.0 \\
\hline $\mathrm{K}_{2} \mathrm{HPO}_{4}$ & 2.0 \\
\hline $\mathrm{MgSO}_{4}$ & 1.0 \\
\hline $\mathrm{CaCl}_{2}$ & 0.02 \\
\hline $\mathrm{FeSO}$ & 0.002 \\
\hline $\mathrm{KCl}$ & 1.0 \\
\hline Trace elements & $1 \mathrm{ml} / 1$ \\
\hline
\end{tabular}

Table-2: Media Components

\begin{tabular}{c|c}
\hline $\mathrm{KH}_{2} \mathrm{PO}_{4}$ & $0.7 \mathrm{~g} / 1$ \\
\hline $\mathrm{Na}_{2} \mathrm{HPO}_{4}$ & $0.9 \mathrm{~g} / 1$ \\
\hline $\mathrm{NaNO}_{3}$ & $2 \mathrm{~g} / 1$ \\
\hline $\mathrm{MgSO}_{4} \cdot 7 \mathrm{H}_{2} \mathrm{O}$ & $0.4 \mathrm{~g} / 1$ \\
\hline $\mathrm{CaCl}_{2} \cdot 2 \mathrm{H}_{2} \mathrm{O}$ & $0.1 \mathrm{~g} / 1$ \\
\hline Trace Elements & $2 \mathrm{ml} / 1$ \\
\hline $\mathrm{CTAB}$ & $0.2 \mathrm{~g} / 1$ \\
\hline Methylene Blue & $0.005 \mathrm{~g} / 1$ \\
\hline Agar & $15 \mathrm{~g} / 1$ \\
\hline
\end{tabular}

\section{Oil Spreading Technique}

This technique was used to correlates surfactant bustle, which is commonly known as the displacement of oil activity. The method used was developed by Masaaki Morikawa et al., 2000. ${ }^{16}$

\section{CTAB-MB}

The test is specifically used for the detection of anionic biosurfactant. A gloomy blue aperture region around the culture should be considered positive for anionic biosurfactant production. ${ }^{17}$

\section{MBAS Assay}

Rhamnolipidproductionwasqualitatively analyzed by methylene blue ActiveSubstanceassay (MBAS) proposedbyHayashi in $1975 .{ }^{16}$

\section{Surface Tension Measurement}

The surface tension of cell-free culture bisque was measured by DuNouyringmethodandtheinstrument usedwasaSurfacetensiometer (USHA INST., Kolkata-73). The surface tension of cell-free culture broth was measured by DuNouyring method. ${ }^{18}$

\section{Rhamnolipid Biosurfactant Recovery}

The culture was centrifuged at $6000 \mathrm{rpm}$ for 15 minutes. The supernatant obtained was used for the extraction method. Then to reduce the $\mathrm{pH}$ to approximately $2,6 \mathrm{~N}$ conc. $\mathrm{HCl}$ was added in supernatant so that it may precipitate. Thus obtained the acidified suspension was kept for overnight in the refrigerator. Chloroform: methanol (2:1 v: v) solvent mixture was used to extract the biosurfactant by using separating funnel. This step was repeated twice. Ethyl acetate was used for the washing of the Organic phase obtained at the bottom. The aqueous phase was discarded. The organic phase was kept open for overnight. It was filtered to obtain crude biosurfactant for further column chromatography, TLC, FTIR, and NMR analysis.

\section{Purification and Characterization of Rhamnolipid Biosurfactant column chromatography}

Liquid column chromatography was used for these variances of rhamnolipids. $50 \mathrm{~g}$ of activated silica gel $60-\mathrm{CHCl}_{3}$ slurry was used for the separation of the polar lipids in a $26 \times 3.3 \mathrm{~cm}$ column. $5 \mathrm{~g}$ sample of rudimentary rhamnolipid primed was loaded in the column in $10 \mathrm{ml}$ Chloroform and then to evade the neutral lipids the column was cleaned away with chloroform. Then at a flow rate of $1 \mathrm{ml} / \mathrm{min}$ and $20 \mathrm{ml}$ fractions were collected by applying the mobile phases of chloroform: methanol in sequence;50:3 
RASĀYAN J. Chem.

Vol. 12 | No. 2 |1011 - 1021| April - June | 2019

$\mathrm{v} / \mathrm{v}(1000 \mathrm{ml}), 50: 5 \mathrm{v} / \mathrm{v}(200 \mathrm{ml})$ and $50: 50 \mathrm{v} / \mathrm{v}(100 \mathrm{ml})^{20}$. A concluding cleanse washing with half-half $\mathrm{CHCl}_{3}$ :

$\mathrm{CH}_{3} \mathrm{OH}$ detached any remaining rhamnolipid from the column. Fractions were pooled and solvent of vigorous fractions enclosing biosurfactant was fade away to dryness beneath vacuum with a rotor evaporator(make - BUCHI ${ }^{\mathrm{TM}}$ Rotavapor $^{\mathrm{TM}} \mathrm{R}-300$ ) at $40^{0}$ Cunderabridgedpressure.

\section{Thin Layer Chromatography}

The fractions from the liquid column chromatography thus obtained. Further $1 \mathrm{ml} \mathrm{CHCl}_{3}$ and $100 \mu \mathrm{lof}$ each sample was taken and the samples were dissolving followed by applying to a $20 \times 20$ silica gel TLC plate and developed in a solvent system of chloroform : methanol : acetic acid $(65: 15: 2 \mathrm{v} / \mathrm{v} / \mathrm{v})$. The separated spots on these preparative TLC plates were carefully scraped and collected separately. From these silica gel scrapings, the rhamnolipids were extracted thrice with $8 \mathrm{ml}$ of $\mathrm{CHCl}_{3}: \mathrm{CH}_{3} \mathrm{OH}(1: 2 \mathrm{v} / \mathrm{v})$. The solvent scraping mixture was vortexed forlminute followed by centrifugation and settled down the silica gel for 10 minutes and pipetted off the solvent. ${ }^{29}$

\section{Effect of Environmental Factors on Biosurfactant Activity}

The outcomes of the accumulation of dissimilar concentrations of salt (sodium chloride) on the bustle of the biosurfactant were investigated in the cell-free broth. Specific concentrations of salt (sodium chloride)(2-10\%, weight/vol) were additionally provided and the surface tension was determined as described above. The cell-free broth was also maintained at a constant temperature $\left(5,70,100\right.$ and $\left.120{ }^{\circ} \mathrm{C}\right)$ for $60 \mathrm{~min}$ and used for surface tension and emulsification measurements. The consequence of the $\mathrm{pH}$ on the surface tension was investigated after fine-tuning of the bisque $\mathrm{pH}$ to 2, 4,6,8,10,12 and 14 with 6.0 Molar $\mathrm{NaOH}$ or $\mathrm{HCl}^{19}$

\section{Application of Biosurfactant in Hydrophobic Contaminant Cleaning Test}

To determine the cleaning ability of the biosurfactant, the inner walls of a beaker were coated with motor oil. Fifty $\mathrm{ml}$ of the cell-free culture broth were added to the beaker, which was vortexed for $1.0 \mathrm{~min}$ and allowed to stand for $6 \mathrm{~h}^{20}$

\section{NMR and FTIR Analysis}

Purified rhamnolipid samples are analyzed with the magnetic nuclear response (NMR) and FTIR. JEOL JNM-ECS400 spectrometer manufactured by Tokyo, Japan was used for ${ }^{1} \mathrm{H}$ and ${ }^{13} \mathrm{C}$ spectrum. FTIR studies were done on PerkinElmer Spectrum Version 10.03.06 manufactured by the USA. ${ }^{21}$

\section{RESULTS AND DISCUSSION}

Rhamnolipids, produced by Pseudomonas species are a kind of glycolipids. The strain was developed on basal salt medium (BSM) and was further screened for biosurfactant production by different assays. Rhamnolipids biosurfactants produced by Pseudomonas aeruginosa was determined by the formation of insoluble ion pairs with various cationic substances.

\section{Oil Displacement Assay}

$10 \mu \mathrm{l}$ of oil was added to the surface of $10 \mathrm{ml}$ distilled water in a plate. A thin layer of oil was formed on the surface of the water. $10 \mu \mathrm{l}$ of cell-free supernatant was placed on the center of oil layer where the clear zone was formed by displacing oil showed the presence of biosurfactant.

\section{Drop Collapse Assay}

$2 \mu 1$ of oil was applied on Petri plate and 2-3 $\mu 1$ of cell-free supernatant was placed on oil drop. It was observed after $1 \mathrm{~min}$. The result was considered positive for biosurfactant production when the drop was flat and the rounded drops were scored as negative. The diameter $(\mathrm{mm})$ of the drop was observed and shown in Table-4.

\section{CTAB Methylene Blue Assay}

This test is specific for the identification of anionic biosurfactant producers. Instead of CTAB other cationic detergents can also be used. Cell-free supernatant was loaded into each well prepared in 
methylene blue agar plate. The plate was then incubated at $37^{\circ} \mathrm{C}$ for $48-72 \mathrm{~h}$. A dark blue hole zone around the culture was considered positive for anionic biosurfactant production.

\section{MBAS Assay}

Rhamnolipid production by the strains Pseudomonas aeruginosa MTCC 424 was qualitatively analyzed by Methylene Blue Active Substanceassay (MBAS). The method was based on the formation of a complex between an anionic surfactant and the cationic dye methylene blue, followed by the extraction of the complex into chloroform and measurement of the absorbance(Table- 6) of the blue chloroform layer at $655 \mathrm{~nm}$. The blue tint of the anionic surfactant-methylene blue complex was observed at the bottom layer of chloroform which confirmed the production of an anionic biosurfactant thus obtained by Pseudomonas aeruginosa MTCC424.

\section{Emulsification Assay (E24)}

$2 \mathrm{ml}$ of oil was added to each test tube where cell-free supernatant was suspended and the mixture was vortexed for $1 \mathrm{~min}$ and allowed to stand for $24 \mathrm{hrs}$. Emulsion layer was formed which was calculated by the known (given above) formula.

Table-3: Emulsification Index for Different Substrate

\begin{tabular}{|c|c|c|c|c|c|}
\hline & Table-3 & mulsification & ndex for & fferent & strate \\
\hline & Substrate & $\begin{array}{c}\text { DCA } \\
\text { (Dia in } \mathrm{mm})\end{array}$ & ODA & CTA & EI (\%) \\
\hline & $\mathrm{RO}$ & $\begin{array}{c}+ \\
5.0\end{array}$ & + & + & 72.20 \\
\hline & Control & - & - & - & 25.92 \\
\hline $\begin{array}{l}+=\text { positive result } \\
-=\text { negative result }\end{array}$ & & le-4: Surface & Tension $\mathrm{N}$ & asurems & \\
\hline & Substrate & $\begin{array}{r}\text { Surface T } \\
\mathrm{C}\end{array}$ & $\begin{array}{l}\text { ision Red } \\
\text { acentratic }\end{array}$ & $\begin{array}{l}\text { tion on } \\
\text { of Sam }\end{array}$ & easing \\
\hline & $\mathrm{RO}$ & 64.77 & 61.10 & 59.44 & 56.46 \\
\hline & Control & 71.49 & 71.48 & 71.44 & 71.44 \\
\hline
\end{tabular}

\section{Surface Tension Measurement}

The surface Tension was decreased throughout the growth of the strain data as given in Table-5.

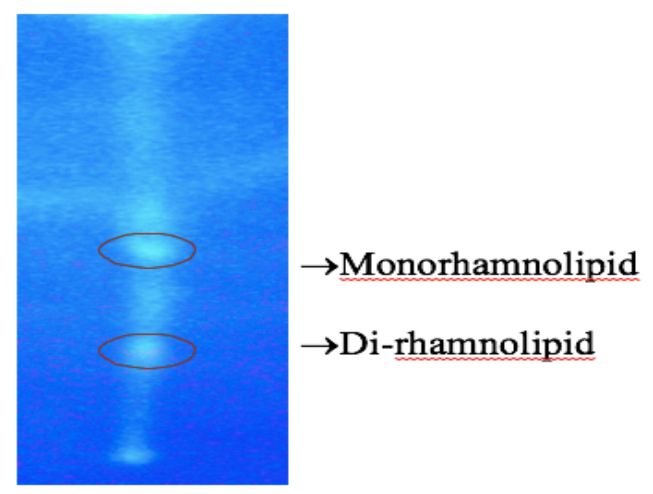

\section{Column Chromatography}

Fig.-1: Thin Layer Chromatography Strip Analysis

Therhamnolipidcomponents produced by the strain P. aeruginosa MTCC 424 using residual rice bran as the substrates were recovered from the batch cultures by centrifugation followed by acid precipitation and solvent extraction. Ethyl Acetate was used as an organic solvent used for the extraction. silica gel column chromatography was used for the further purification of the resulting partially purified rhamnolipid components and collected fractions were analyzed byTLC in order to monitor the separation of the components. 


\section{Thin Layer Chromatography}

As shown in Fig.-1, the Blue acne investigative of carbohydrate units were noticed on spraying with anisaldehyde reagent (Sigma Aldrich) in silica plates encumbered with crude extract of the biosurfactant produced by Pseudomonas aeruginosa MTCC424. When the similar plates w e r e bared with iodine vapor, yellow acne investigative of lipids benevolent equivalent Retention factor as that of glycosyl units was acquired on the identical section. The occurrence of both glycosyl units and lipid moieties on the same acne indicated that the sample was a glycolipid and the Retention factor acquired was 0.62, analogous to that of rhamnolipids. ${ }^{28}$ In the previous study, the presence of both glycosyl units and lipid moieties on the spot with $\mathrm{Rf}_{\mathrm{f}}$ value 0.65 indicated the presence of a rhamnolipid biosurfactant. Another spot with a lower $\mathrm{Rf}$ value 0.26 was seen with this sample which also showed the presence of glycosyl and carbohydrate moiety. These results showed that the strain Pseudomonas aeruginosa MTCC424 was able to grow and produce rhamnolipid biosurfactant.

\section{Optimization of Incubation Time on Biosurfactant Production}

The optimum incubation time for rhamnolipid production by Pseudomonas aeruginosa MTCC424 using residual rice bran was found to be 7 days (Fig.-2).

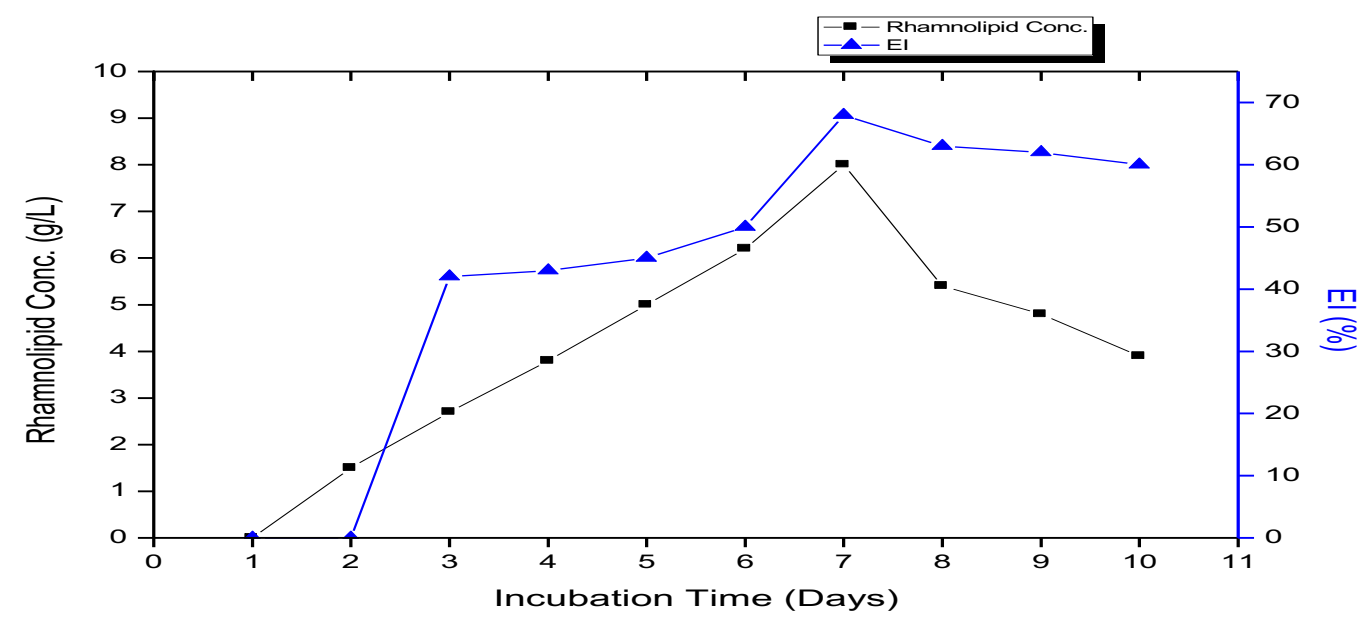

Fig.- 2 : Effect of Incubation Time on Rhamnolipid Production and Emulsification Index(\%) with Mineral Oil by Pseudomonas aeruginosa MTCC424 using Residual Rice Bran (4\%) Oil as the Solitary Carbon Source.

\section{Optimization of Substrate Concentration on Biosurfactant Production}

The rhamnolipid production by both bacterial strains was studied with varying concentrations of selected substrates in the growth medium. The rhamnolipid production by Pseudomonas aeruginosa MTCC 424 showed a significant increase with the increase in the rice bran concentration and attained the maximum yield when $4 \%$ rice bran oil was used as the carbon source(Fig.-3).

\section{Optimization of pH on Biosurfactant Production}

The optimum $\mathrm{pH}$ of the medium for maximum biosurfactant yield by Pseudomonas aeruginosa MTCC424 using residual rice bran was found to be 6.8(Fig.-5). The production decreased with the increase in $\mathrm{pH}$ beyond 6.8 .

\section{Effect of Environmental Factors on Biosurfactant Activity}

Salinity, temperature and $\mathrm{pH}$ are various parameters on which the production of biosurfactant depends. ${ }^{20}$ Therefore the effect on the variation of these parameters on the production of biosurfactant was tested and described as per given in Table-6. At $\mathrm{pH} 2,4$ and 6, a very slight increase in surface tension was found. At $\mathrm{pH}$ in the range from 3-5(acidic) the rhamnolipid produced by P.aeruginosa as analyzed and found complete inactivation of the emulsifying capacity, but at higher values ie 6-9 no significant changes. With 
the different concentration of salt, it was observed that the surface tension of the cell-free broth containing the biosurfactant proved stable. It was observed that at $\mathrm{NaCl}$ concentration above $10 \%$, there was approximately no reduction in surface tension caused by a biosurfactant produced from the bacterial strain. ${ }^{22}$ The surface tension of the cell-free broth underwent small changes at different temperatures tested, with an as light increase at $5^{\circ} \mathrm{C}$, but the results were unaltered at $(26-27 \mathrm{mN} / \mathrm{m})$ at high temperatures $\left(70,100\right.$ and $\left.120^{\circ} \mathrm{C}\right)$.

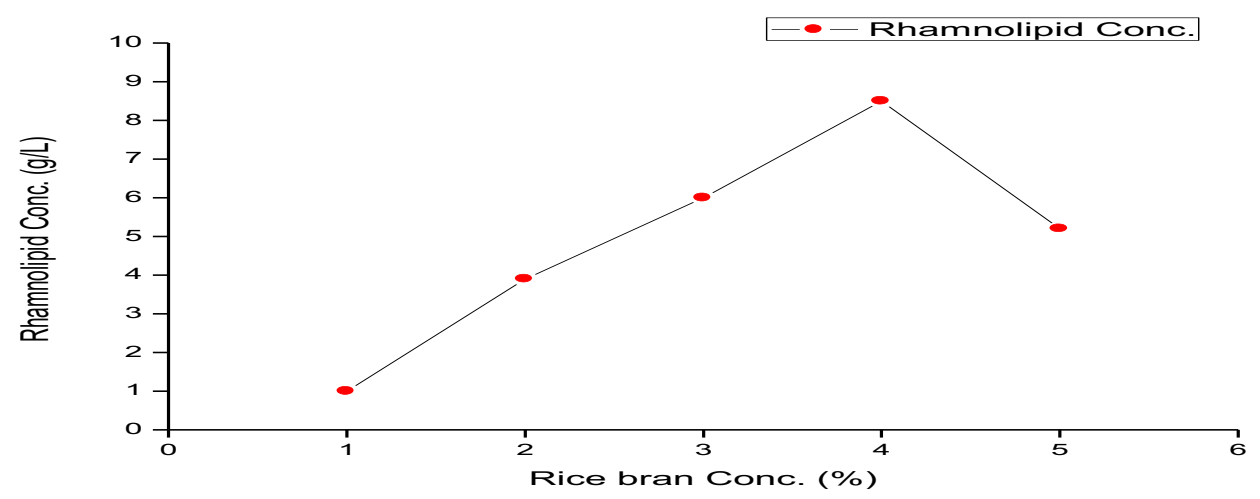

Fig.-3: Effect of Concentration of Rice Bran as the Carbon Source on Biosurfactant Production using Pseudomonas aeruginosa MTCC424(pH 6.8, Incubation Time 7 days).

\section{Chemical Characterization of Purified Biosurfactant}

As revealed in Fig.-6 the FTIR analysis, an extensive elongate at $3417 \mathrm{~cm}^{-1}$ that was an attributed elongation mode of - $\mathrm{OH}$ group can be experiential undoubtedly. The symmetric elongate $(-\mathrm{C}-\mathrm{H})$ of $-\mathrm{CH}_{2}-$ and $-\mathrm{CH}_{3}$ groups of aliphatic manacles were represented by the absorption bands around $2927 \mathrm{~cm}^{-1}, 2856$ $\mathrm{cm}^{-1}$ and $1402 \mathrm{~cm}^{-1}$ represented, and an absorption band at $722 \mathrm{~cm}^{-1}$ was assigned to $-\left(\mathrm{CH}_{2}\right)_{\mathrm{n}^{-}}(\mathrm{n}=6)$ group. Also, a concerted assimilation band at $1572 \mathrm{~cm}^{-1}$ and $1068 \mathrm{~cm}^{-1}$ indicated the company of $-\mathrm{C}=\mathrm{O}$ group and -C-O-C- group, respectively. Additionally, a weak absorption band at $1722 \mathrm{~cm}^{-1}, 1651 \mathrm{~cm}^{-1}$, $1377 \mathrm{~cm}^{-1}, 1124 \mathrm{~cm}^{-1}$ and $982 \mathrm{~cm}^{-1}$ was the unsaturated alkyl double bond $(-\mathrm{C}=\mathrm{C}-)$ of aliphatic chains. Compared with the previous literature ${ }^{23}$, these main chemical structure groups were in agreement with the characteristic of rhamnolipid.

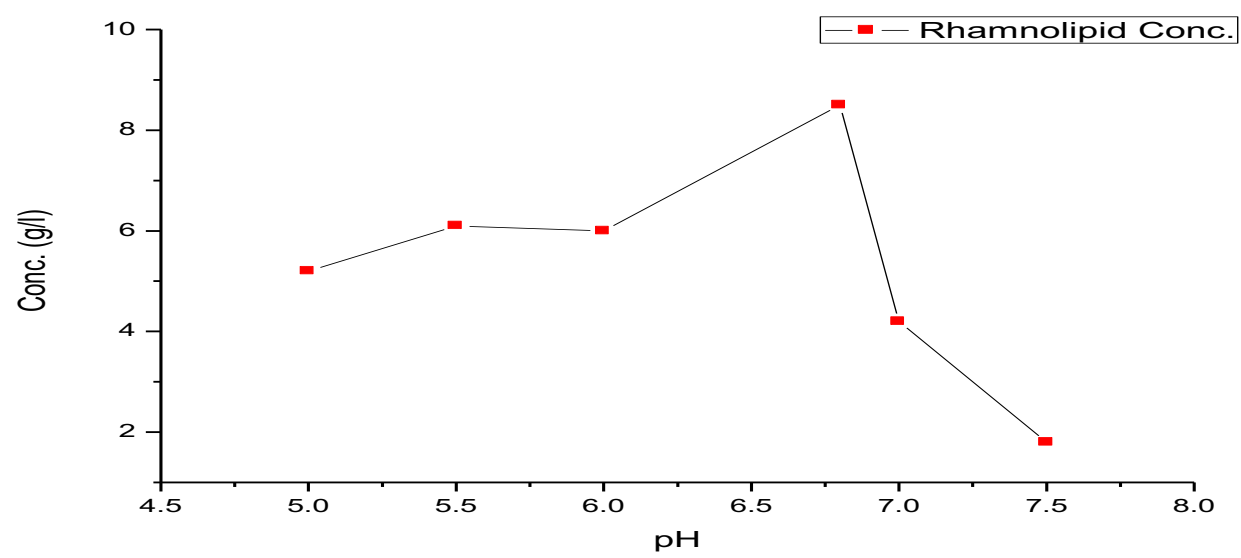

Fig.-4: EffectofpHonBiosurfactantProductionbyPseudomonas aeruginosaMTCC424usingRice Bran OilastheCarbon Sourceat 4\% Level (Incubation Time7days).

The detail chemical structure groups of the biosurfactant were identified by NMR. Structure information is obtained from three parameters: chemical shifts of the absorption frequency, coupling (mutual influence of adjacent nuclei), and integral height. ${ }^{24}$ 
RASĀYAN J. Chem.

Vol. 12 | No. 2 |1011 - 1021| April - June | 2019

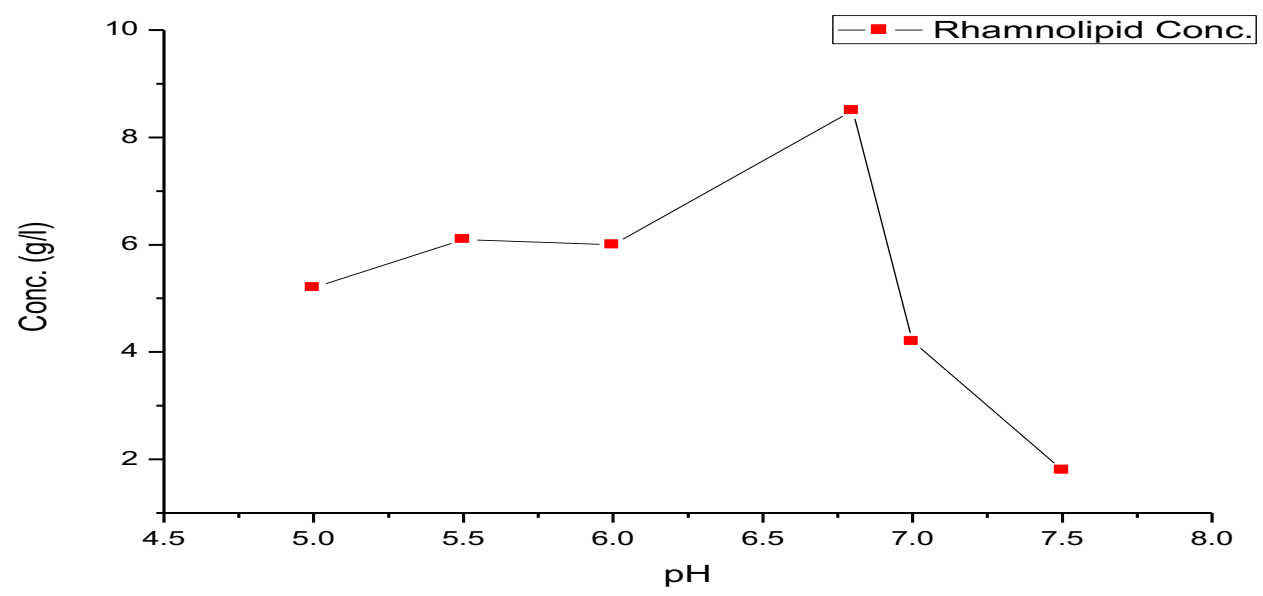

(a)

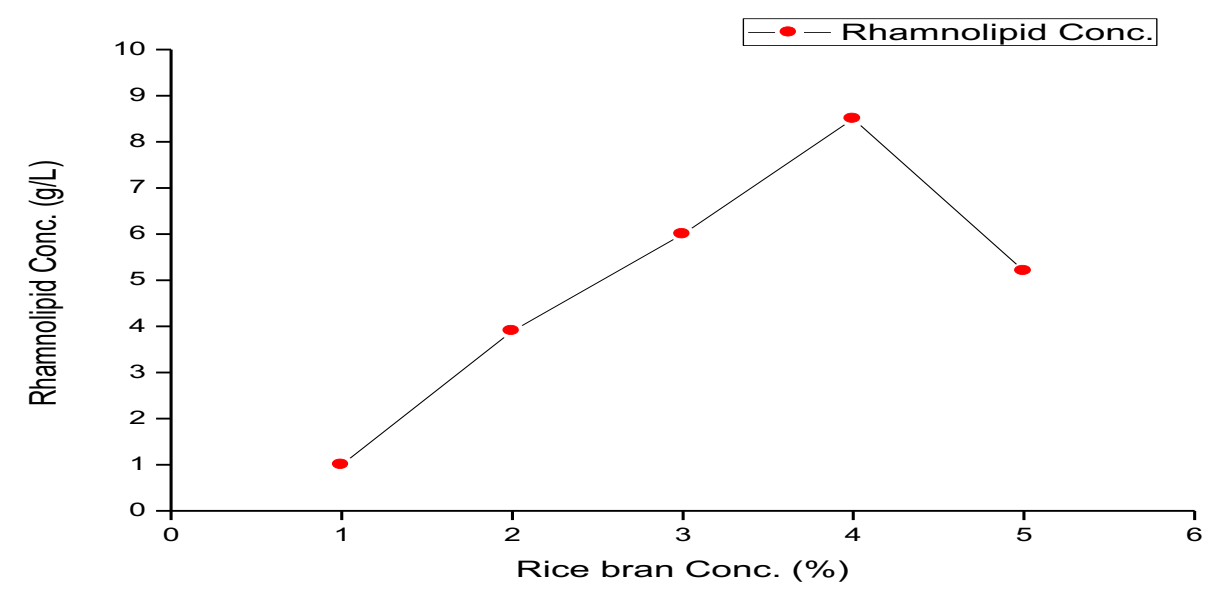

(b)

Fig.-5: (a)pH Versus Rhamnolipids Concentration produced from P. aeruginosa MTCC424, (b) Residual Rice Bran Oil $(\%)$ Concentration Vs Rhamnolipid produced (g/l) Concentration

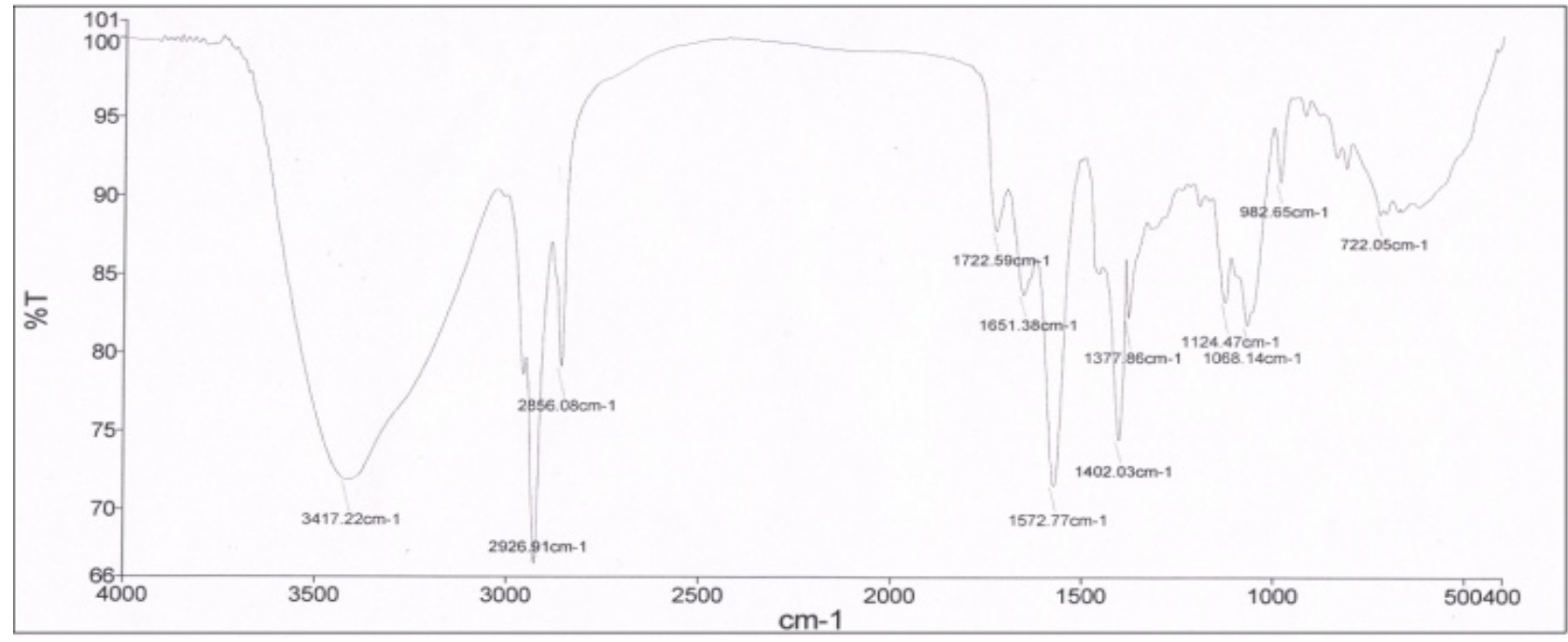

Fig.-6: FT-IR Spectra of the purified Biosurfactant produced by Pseudomonas ae. 424. 
RASĀYAN J. Chem.

Vol. 12 | No. 2 |1011 - 1021| April - June | 2019

Table-5: Effect of Salt Concentration, Temperature and $\mathrm{pH}$ on Surface Tension (ST) of Cell-Free Broth Containing Biosurfactant from P.aeruginosa MTCC424 with $4 \%$ RO for $48 \mathrm{~h}$ at $100 \mathrm{rpm}$ and $25{ }^{\circ} \mathrm{C}$.

\begin{tabular}{c|c}
\hline & $\mathrm{ST}(\mathrm{mN} / \mathrm{m})$ \\
\hline $\mathrm{NaCl}(\%)$ & $25.9 \pm 0.03$ \\
0.0 & $26.2 \pm 0.05$ \\
3.0 & $27.1 \pm 0.06$ \\
6.0 & $27.2 \pm 0.04$ \\
9.0 & $27.5 \pm 0.08$ \\
10.0 & $27.7 \pm 0.01$ \\
12.0 & $27.7 \pm 0.02$ \\
15.0 & \\
Temperature $\left({ }^{\circ} \mathrm{C}\right)$ & $29.1 \pm 0.04$ \\
5 & $26.2 \pm 0.07$ \\
70 & $27.9 \pm 0.03$ \\
100 & $27.1 \pm 0.02$ \\
120 & \\
$\mathrm{pH}$ & $32.9 \pm 0.06$ \\
2 & $33.2 \pm 0.04$ \\
3 & $33.5 \pm 0.06$ \\
4 & $33.8 \pm 0.05$ \\
5 & $33.7 \pm 0.01$ \\
6 & $33.8 \pm 0.01$ \\
7 & $33.7 \pm 0.09$ \\
8 & $33.7 \pm 0.07$ \\
9 &
\end{tabular}

Table: 6 Chemical Shift of cleansed Rhamnolipid in ${ }^{1} \mathrm{H}$ NMR and ${ }^{13} \mathrm{C}$ NMR Spectra

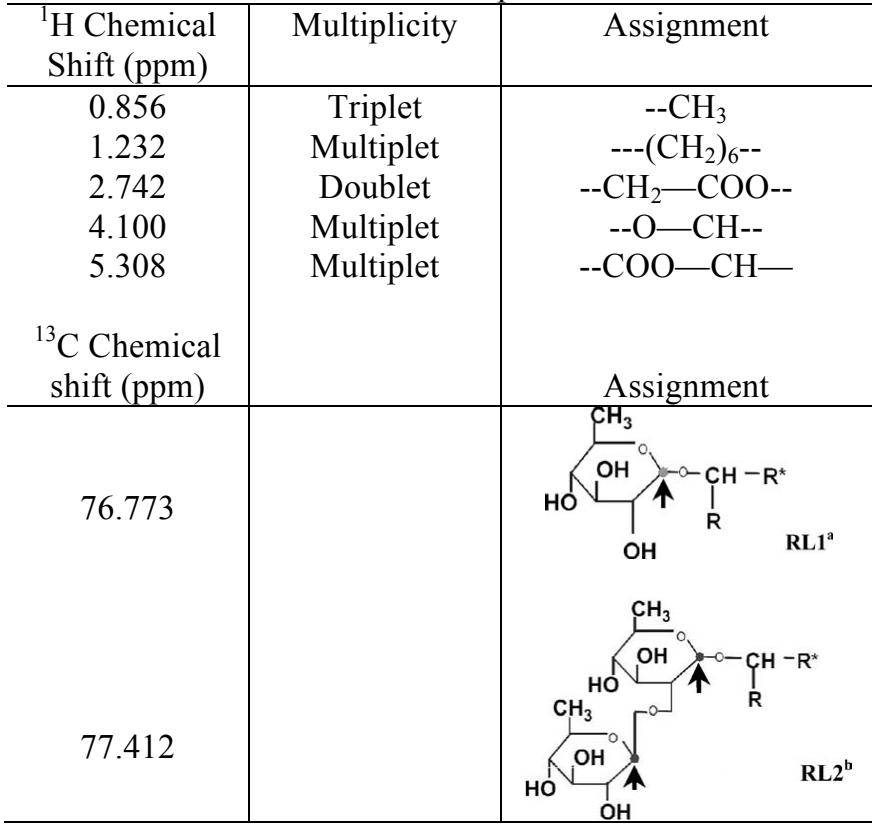

${ }^{a}$ RL1 (rhamnolipid 1): L-rhamnosyl-b-hydroxydecanoyl-b-hydroxydecanoate

${ }^{\mathrm{b}} \mathrm{RL} 2$ (rhamnolipid 2): L-rhamnosyl L-rhamnosyl-bhydroxydecanoyl-b-hydroxydecanoate

The purified rhamnolipid was analyzed by NMR as shown in Fig.-7 and Table-6. In the ${ }^{1} \mathrm{H}$ NMR study The distinguishing chemical shifts pragmatics were $0.855 \mathrm{ppm}$ (for $\left.-\mathrm{CH}_{3}\right), 1.232 \mathrm{ppm}$ (for $-\left(\mathrm{CH}_{2}\right)_{6}$ ), $2.742 \mathrm{ppm}$ (for $-\mathrm{CH}_{2}-\mathrm{COO}-$ ), $4.100 \mathrm{ppm}$ (for $-\mathrm{O}-\mathrm{CH}-$ ), and $5.308 \mathrm{ppm}$ (for $-\mathrm{COO}-\mathrm{CH}-$ ). The ${ }^{13} \mathrm{C}$ NMR also displayed chemical shifts of $76.773 \mathrm{ppm}$ (characteristic of RL1) and $77.412 \mathrm{ppm}$ (characteristic of RL2). All those results indicate the molecular structure of L-rhamnosyl-b- 
hydroxydecanoyl-b-hydroxydecanoate (RL1) and L-rhamnosyl-Lrhamnosyl-b-hydroxydecanoyl-bhydroxydecanoate (RL2), which are common rhamnolipids types produced by P. aeruginosastrains. ${ }^{21,22}$

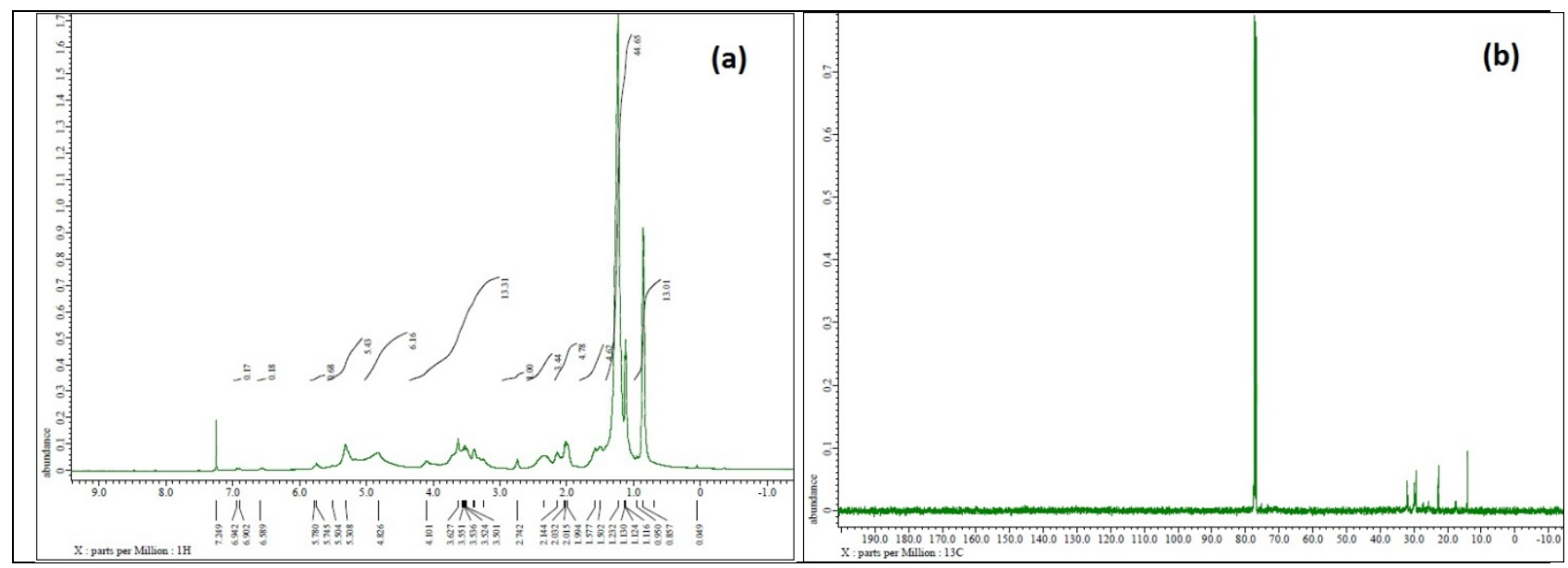

Fig.-7: (a) ${ }^{1} \mathrm{H}$ NMR Spectra, (b) ${ }^{13} \mathrm{C}$ NMR Spectra of the purified Biosurfactant produced by Pseudomonas ae. 424

\section{CONCLUSION}

The present study emphasis on strategies such as the use of cheaper substrates like spent earth which is a waste product of the vegetable oil processing industry so as to reduce the cost of the production of biosurfactant as compare to the conventional substrates like glucose and glycerol etc. and to the optimization of their production parameters. The main obstacle in the production of biosurfactant on a large scale is the costly substrates. In this study using the cheaper substrate like spent earth can make biosurfactant production economically feasible. Some other cheaper substrates like plant-derived oils, oil waste, distillery waste, etc are best supportive for biosurfactant production. Here optimization and production strategy have to be studied for the culture medium to increase the productivity of biosurfactant. The yield of rhamnolipids produced was 8.5 $\mathrm{g} / \mathrm{l}$. The optimum $\mathrm{pH}$ at which the maximum yield of rhamnolipids found was 6.8. In the whole study, the best results were obtained when pure biosurfactant was used, it reduced insufficient production cost and thus improved the adequate industrial application.

\section{ACKNOWLEDGMENT}

I am thankful to MTCC Chandigarh for providing the bacteria culture and Kanpur edible oil (Mayur Group) for providing spent earth. I am also thankful to the Department of Biotechnology, AITH Kanpur, Deptt of Oil Technology, HBTU Kanpur and IIT Kanpur for providing laborites facilities and Director AITH Kanpur for her kind support. I am also thankful to our colleagues who provided impending and proficiency that significantly assisted to follow a line of investigation and research.

1. J. D. Desai, J. Sci. Ind. Res., 46, 440(1987).

\section{REFERENCES}

2. A. Daverey and K. Pakshirajan, App. Biochem. Biotech., 158, 663(2008), DOI:10.1007/s12010-0088449-z

3. F. Ahimou, P. Jacques, M. and Dele, Enz. Mtcrob. Techno., 27, 749(2000), DOI:10.1016/S01410229(00)00295-7

4. M. Nitschke, S. G. V. A. Coasta and J. Contiero, Biotech. Prog., 1, 593(2005).

5. S. Mukherjee, P. Das and R. Sen, TRENDS in Biotechnology, 24(11), 509(2006), DOI: 10.1016/j.tibtech.2006.09.005

6. A. Fiechter, Tibtech., 10, 208(1992), DOI:10.1016/0167-7799(92)90215-H

7. K. Dubey and A. Juwarkar, World Journal of Microbiology and Biotechnology, 17(1), 61(2001), DOI:10.1023/A:1016606509385

8. Y. Zhang, and R. M. Miller, Appl. Environ. Microbiol., 58, 3276 (1992). 
RASĀYAN J. Chem.

Vol. 12 | No. 2 |1011 - 1021| April - June | 2019

9. M. E. Mercade, M. A. Manresa, J. American Oil Chem. Soc., 71(1), 61(1994), DOI: $10.1007 / \mathrm{BF} 02541473$

10. Z. A. Raza, A. Rehman, M. S. Khan and Z. M. Khalid, Biodegradation, 18(1), 115(2007), DOI: $10.1007 / \mathrm{s} 10532-006-9047-9$

11. R. Makkar and S. Cameotra, Applied Microbiology and Biotechnology, 58(4), 428(2002), DOI:10.1007/s00253-001-0924-1

12. S. Maneerat, Songklanakarin J. Sci. Technol., 27(3), 675(2005).

13. G. Dashiny, Oil Recovery from Palm Oil Solid Wastes (Doctoral Dissertation, Dissertation University, Malaya Pahang) (2009).

14. A. A Bodour and R. M. Miller-Maier, Journal of Microbiological Methods, 32(3), 273 (1998), DOI:10.1016/S0167-7012(98)00031-1

15. V. Saravanan and S. Vijayakumar, J. Acad. Indus. Res., 1(5), 264(2012).

16. Noha H. Youssef et al., Journal of Microbiological Methods, 56(3), 339(2004), DOI:10.1016/j.mimet.2003.11.001

17. N. M. Pinzon and L. K. Ju, Biotechnology Letters, 31(10), 1583(2009), DOI: 10.1007/s10529-0090049-7

18. A. A. Bodour and R. M. Miller-Maier, Journal of Microbiological Methods, 32(3), 273(1998), DOI: $10.1016 / \mathrm{S} 0167-7012(98) 00031-1$

19. M. O. Ilori, C. J. Amobi and A. C. Odocha, Chemosphere, 61(7), 985(2005), DOI: 10.1016/j.chemosphere.2005.03.066

20. I. M. Banat, Bioresource Technology, 51(1), 1(1995), DOI: 10.1016/0960-8524(94)00101-6

21. M. Heyd, A. Kohnert, T.H. Tan, M. Nusser, F. Kirschhöfer, G. Brenner-Weiss, M. Franzreb and S. Berensmeier, Analytical and Bioanalytical Chemistry, 391(5), 1579(2008), DOI:10.1007/s00216007-1828-4

22. N. M. P. R. e Silva, R. D. Rufino, J. M. Luna, V. A Santos and L. A. Sarubbo, Biocatalysis and Agricultural Biotechnology, 3(2), 132(2014), DOI: 10.1016/j.bcab.2013.09.005

23. S. Lang, D. Wullbrandt, Appl. Microbiol. Biotechnol., 51, 22(1999), DOI:10.1007/s002530051358

24. O. Pornsunthorntawee, P. Wongpanit, S. Chavadej, M. Abe and R. Rujiravanit, Bioresource Technology, 99(6), 1589(2008), DOI:10.1016/j.biortech.2007.04.020

[RJC-5073/2018] 